\title{
Response to dietary-induced energy restriction in dairy sheep divergently selected for resistance or susceptibility to mastitis
}

\author{
J. Bouvier-Muller, ${ }^{*} \dagger^{1}$ C. Allain, ${ }^{* 1}$ F. Enjalbert, ${ }^{*}$ G. Tabouret, $\dagger$ D. Portes,$\ddagger$ C. Caubet,$\dagger$ C. Tasca, $\dagger$ G. Foucras, $\dagger^{2}$ \\ and R. Rupp*2,3 \\ *INRA, Unité Mixte de Recherche (UMR) 1388 Génétique, Physiologie et Systèmes d'Elevage, F-31326, Castanet-Tolosan, France \\ †Université de Toulouse, École Nationale Vétérinaire de Toulouse (ENVT), INRA, UMR 1225, Interactions Hôtes-Agents Pathogènes (IHAP), \\ F-31076 Toulouse, France \\ †INRA, Unité Expérimentale 0321 Domaine de La Fage, F-12250 Roquefort sur Soulzon, France
}

\begin{abstract}
Dairy ruminants experiencing a severe postpartum negative energy balance (NEB) are considered to be more susceptible to mastitis. Although the genetic variability of mastitis resistance is well established, the biological basis of the link between energy metabolism and resistance is mostly unknown. The aim of this study was to characterize the effect of NEB on metabolism and immune response according to the genetic background for mastitis resistance or susceptibility. Fortyeight ewes from high and low somatic cell score (SCS) genetic lines were allocated to 2 homogeneous subgroups 2 wk after lambing: one group (NEB) received an energy-restricted diet to cover $60 \%$ of their energy requirements, and the other group received a control (positive energy balance: PEB) diet. Both diets met the protein requirements. After $10 \mathrm{~d}$ on either the NEB or PEB diet, all ewes were injected with a Pam3CSK4/ MDP solution in one half-udder to induce an inflammatory response. The ewes were monitored for milk production, somatic cell count (SCC), body weight (BW), body condition score (BCS), and blood metabolites. Differential milk cell counts were determined by flow cytometry. Plasma concentrations of glucose, insulin, nonesterified fatty acids (NEFA), $\beta$-hydroxybutyrate (BHB), and triiodothyronine were determined. Energy restriction resulted in an increased fat:protein ratio in milk and decreased milk yield, BW, and BCS. The NEB ewes had significantly higher NEFA and BHB and lower plasma glucose concentrations than PEB ewes, reflecting a mobilization of body reserves and ketone
\end{abstract}

Received May 6, 2015.

Accepted August 9, 2015.

${ }^{1}$ These authors contributed equally to this work.

${ }^{2}$ These authors share senior authorship.

${ }^{3}$ Corresponding author: rachel.rupp@toulouse.inra.fr body synthesis. High-SCS ewes had a higher SCS than low-SCS throughout the experiment, except after the inflammatory challenge, which resulted in similar SCS in all 4 groups. A noteworthy interaction between genetic background and diet was evidenced on metabolic parameters and BW. Indeed, high-SCS ewes subjected to NEB showed greater decrease in BW and increased NEFA and BHB concentrations compared with lowSCS ewes. Thus, NEB in early lactation led to extensive mobilization of body reserves and intense ketone body synthesis in mastitis-susceptible sheep. These results reinforce the hypothesis of a genetic association between mastitis susceptibility and energy metabolism and open the way to further studies on the biological basis for this association.

Key words: mastitis susceptibility, negative energy balance, dairy ruminant

\section{INTRODUCTION}

Mastitis is considered the most frequent and costly disease of dairy cattle (Barkema et al., 2009) and sheep (Bergonier et al., 2003), which makes it one of the major concerns in dairy production. The highly successful selection for milk production achieved over recent decades has led to a poorer mastitis resistance (Heringstad et al., 2005). Thus, genetic improvement might be a useful option for diminishing mastitis frequency. In this context, we developed a divergent breeding protocol in Lacaune dairy sheep based on extreme values of logtransformed SCC (Rupp et al., 2009). Measurements of the frequency and duration of bacteria in milk (Rupp et al., 2009) showed that low-SCS and high-SCS ewes have lower and higher rate of IMI in natural conditions, respectively. Additionally, bacteriological titer after experimental challenge (Bonnefont et al., 2011) in the 2 genetic lines (high vs. low SCS) demonstrated that bacterial clearance is more efficient in low-SCS ewes 
than in the high-SCS ewes. Accordingly, low-SCS and high-SCS ewes were further defined as high- and lowresistant sheep.

Increased susceptibility to mastitis during the peripartum period has been widely documented, as reviewed by Mallard et al. (1998). The potential role of a functional link between the immune and endocrine systems during the peripartum period has been mentioned. Dairy cattle experiencing a severe negative energy balance (NEB) are considered to be more susceptible to mastitis (Suriyasathaporn et al., 2000; Goff, 2006). Some degree of NEB can be expected during the periparturient period due to the increased energy required to support lactation coupled with a reduced feed intake (Drackley, 1999), especially in high milk-producing animals. The severity and duration of NEB associated with early lactation lead to extensive mobilization of FA from the adipose tissue and result in higher blood nonesterified fatty acids (NEFA) or BHB concentrations, or both (Dann et al., 2006).

Several studies have reported an impairment of immune functions in response to increased concentrations of FA and ketone bodies in vitro. The phagocytic and bactericidal capacities of polymorphonuclear neutrophils (PMNL) in vitro are impaired by ketone body concentrations similar to those observed around parturition (Suriyasathaporn et al., 1999). Moreover, Scalia et al. (2006) showed that high concentrations of NEFA reduced bovine PMNL viability in vitro. However, the mechanisms behind the relationship between energy balance and immune function in vivo remain unclear.

Although large-scale studies demonstrated an association between NEFA and BHB and the risk of mastitis during early lactation (Jánosi et al., 2003; Nyman et al., 2008), no firm conclusions could be drawn from studies based on diet-induced NEB models. For instance, Moyes et al. (2009) fed mid lactation cows with either $60 \%$ of their maintenance requirements or ad libitum. Diet had no effect on the chemotaxis of blood neutrophils and only a slight effect on phagocytosis capability.

Several studies have reported positive genetic associations between mastitis and ketosis (Heringstad et al., 2005; Zwald et al., 2004). Moreover, Koeck et al. (2014) recently showed that a lower BHB during the early stages of lactation was genetically associated with less frequent clinical ketosis (genetic correlation $=$ 0.48) and lower SCC (Pearson correlations with EBV $=0.11)$. Altogether, these studies support a biological and genetic association between mastitis and metabolic diseases in early lactation. However, to our knowledge, the direct relationship between early lactation NEB and genetic predisposition to mastitis has never been investigated in vivo. Hence, our model of divergent genetic lines provides a unique opportunity to examine the response of ewes with contrasting genetic backgrounds in mastitis susceptibility to metabolic stress. Our objective was therefore to determine the consequences of experimentally induced NEB during early lactation on production traits and metabolic response in 2 divergent genetic lines, respectively selected for either enhanced or reduced resistance to mastitis.

\section{MATERIALS AND METHODS}

The experiment was carried out following the procedures approved by the Ethics Committee on Animal Experimentation of Toulouse (France), Agreement $01557 / 01$.

\section{Animals}

Forty-eight primiparous Lacaune ewes bred at the INRA experimental facility of La Fage (UE321, Roquefort, France) were used for the study. They were enrolled 5 wk before their first lambing until 1 mo after lambing. They belonged to the 2 genetic lines, high and low SCS, divergently selected as described in Rupp et al. (2009). Briefly, the ewes were obtained by one-generation divergent selection of French Lacaune dairy ewes based on dams and progeny-tested rams selected for extreme breeding values for log-transformed SCC. Previous studies had shown that low-SCS ewes are characterized by higher mastitis resistance than high-SCS ewes (Rupp et al., 2009). Ewes in both genetic lines (high vs. low SCS) were housed together in the same facility and managed identically. After lambing, the ewes were left with their lamb for $24 \mathrm{~h}$ to allow colostrum consumption. After $24 \mathrm{~h}$, the lambs were removed and fed a milk replacer. The ewes were then machine-milked together, in no predefined milking order, twice a day (0800 and $1700 \mathrm{~h}$ ) and had free access to water. The bedding before lambing was straw and wood shavings thereafter.

\section{Experimental Design and Diets}

A preliminary phase was instigated 5 wk before lambing to adapt the ewes to the diet and individual feeding system. This system was electronically controlled to allow access of each animal to its correct place and to measure the refused feed. As shown in Figure 1, the experiment per se consisted of 4 phases: a postlambing adjustment period, an energy restriction period, an inflammatory challenge period, and a postrestriction period. Phase 1 consisted of a 2 -wk period of adjustment after lambing during which individual measurements were taken to calculate the amount of feed to be 


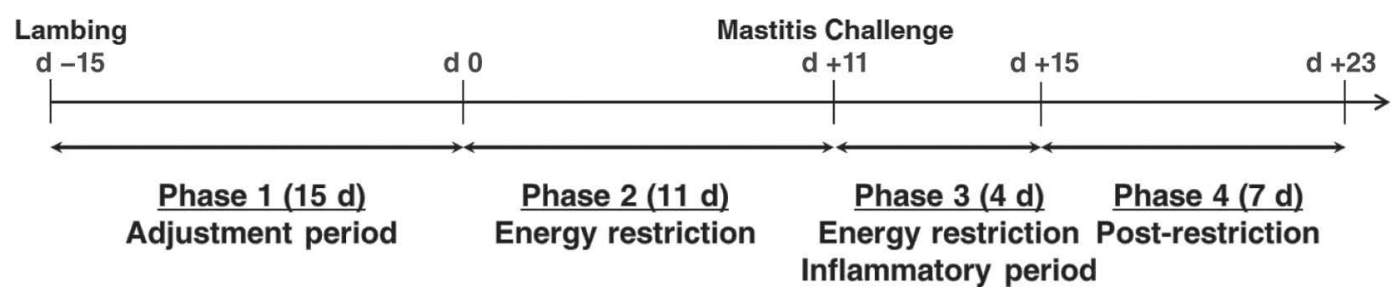

Figure 1. Experiment timeline.

offered thereafter and to constitute the experimental groups. These groups were based on the genetic line (high-SCS or low-SCS) and diet, namely NEB ewes, which were restricted during phases 2 and 3 , and those which received a control diet to ensure a positive energy balance: PEB ewes. The ewes were randomly assigned to either the NEB or PEB groups to obtain 4 balanced groups of 12 ewes according to milk yield, milk composition, BW, and litter size: high-SCS PEB, low-SCS PEB, high-SCS NEB, and low-SCS NEB. Phase 2 consisted of an 11-d period during which a NEB was induced in NEB ewes by decreasing the energy supply. Ewes in the NEB group received $60 \%$ of their energy requirements and $100 \%$ of their protein requirements, calculated from the individual data collected in phase 1. The first day of restriction was referred to as $\mathrm{d} 0$ in the experiment timeline. Phase 3 consisted of a $4-d$ period, starting on d 11, during which all ewes received a mammary injection of a mixed Pam3CSK4/Muramyl Dipeptide (MDP) solution to induce local inflammation. The NEB and PEB diets were maintained during this challenge phase. During phase 4, the NEB ewes were progressively returned to a control diet, which was achieved 5 d later.

After lambing, the ewes received $2.93 \mathrm{~kg} / \mathrm{d}$ of TMR (Table 1) given in 2 equal meals at 0900 and $1630 \mathrm{~h}$, and $0.4 \mathrm{~kg} / \mathrm{d}$ of barley distributed during the 2 milking periods. This control diet was designed to allow ad libitum intake and full coverage of energy and protein requirements (Hassoun and Bocquier, 2014). During phases 2 and 3, the barley distributed at the milking parlor for the NEB ewes was replaced by $0.4 \mathrm{~kg} / \mathrm{d}$ of protein supplement (Brebitanne, RAGT, Albi, France) and the amount of TMR was individually adjusted so that the TMR plus protein supplement met either $60 \%$ or more than $100 \%$ of the energy and protein requirements, respectively. The amounts of TMR were not readjusted during phases 2 and 3 . These requirements were calculated from the individual production and BW data obtained during phase 1 and the amount of TMR given to NEB ewes remained unchanged throughout the entire energy restriction phase. On average, NEB ewes consumed $1.51 \mathrm{~kg} / \mathrm{d}$ of TMR (ranging from 0.7 to $1.9 \mathrm{~kg}$ ) during the restriction phase.

\section{Energy Requirement and Energy Balance Calculation}

For each ewe, the DMI was calculated from the offered feed minus the refused feed, as measured by the individual feeding system, and the energy requirement was calculated at $\mathrm{d}-8,-7,-6,-2$, and -1 according to Hassoun and Bocquier (2014), taking into account milk production and composition. Energy balance was calculated as

$$
\begin{gathered}
\mathrm{EB}=\left(\mathrm{DMI} \times \mathrm{NE}_{\mathrm{L}} \mathrm{c}-\text { energy requirement }\right) / \\
\text { energy requirement } \times 100 .
\end{gathered}
$$

where $\mathrm{NE}_{\mathrm{L}} \mathrm{C}$ is the net energy content of the diet.

\section{Intramammary Challenge with Pam3CSK4/MDP}

A sterile solution of Pam3CSK4 (10 $\mu \mathrm{g} / \mathrm{mL}$, InVivogen, Toulouse, France) and MDP $(10 \mu \mathrm{g} / \mathrm{mL}$, InVivogen) was prepared in PBS (Life Technologies SAS, Saint Aubin, France) containing 0.1\% ovalbumin (Sigma-Aldrich, Saint-Quentin Fallavier, France). The solution was filter-sterilized and stored at $4^{\circ} \mathrm{C}$ until injection. On d 11 of the restriction phase, the healthiest half-udder was chosen during the morning milking according to the SCS and emptied manually. The tips

Table 1. Nutrient composition of feed

\begin{tabular}{lccc}
\hline $\begin{array}{l}\text { Nutrient } \\
\text { (DM basis) }\end{array}$ & $\begin{array}{c}\text { Lactation } \\
\text { TMR }^{1}\end{array}$ & Barley & $\begin{array}{c}\text { Protein } \\
\text { supplement }\end{array}$ \\
\hline CP (\%) & 16.3 & 12.7 & 45.8 \\
Crude fat (\%) & 3.4 & 4.2 & 2.8 \\
Ash (\%) & 11.9 & 2.4 & 7.2 \\
Starch (\%) & 2.8 & 55.9 & 0.1 \\
NDF (\%) & 39.9 & 22.5 & 20.6 \\
ADF (\%) & 26.7 & 5.9 & 12.5 \\
P (\%) & 0.40 & 0.5 & 0.8 \\
NE $(\mathrm{Mcal} / \mathrm{kg})$ & 1.23 & 1.90 & 1.96 \\
Ca (\%) & 1.36 & 0.1 & 0.6 \\
\hline
\end{tabular}

${ }^{1}$ Contained ( $\%$ as fed) $79.5 \%$ dehydrated alfalfa, $2.2 \%$ extruded linseed, $8.25 \%$ common wheat, $5 \%$ cane molasses, $3.6 \%$ rapeseed, $1 \%$ sodium bicarbonate, $0.2 \%$ sodium chloride. 
of the teats were disinfected twice with a compress containing $70 \%$ alcohol. The teat canals were catheterized before injection of $1 \mathrm{~mL}$ of the Pam3CSK4/MDP solution. Immediately after injection, the cannula was removed and the udder was massaged to facilitate diffusion of the injected solution.

\section{Milk Production Traits and SCS}

Milk yield, fat, and protein contents and SCC were measured 4 times a week, twice per day, from samples collected during the morning and evening milkings. All analyses were performed with a Fossmatic cell counter (Foss, Nanterre, France) at the Interprofessional Milk Analysis Laboratory (Aurillac, France). Daily values of SCC, fat and protein yields, and fat and protein contents were then calculated as the average of the morning and evening milking values. The average SCC, fat content, and protein content were weighed by milk yield. The daily fat-to-protein ratio $(\mathbf{F}: \mathbf{P})$ was calculated from the daily averages for fat and protein contents. The data were then normalized by log-transforming the daily SCC to a daily SCS as follows: SCS $=3+\log 2$ (SCC/100,000; Shook, 2006). A reference milk production (MILKREF) was then calculated, for each ewe, as the average of the last 3 milk yields recorded during phase 1 (i.e., during the second week after lambing). In addition, half-udder foremilk samples were collected from each ewe and used to measure SCC at d 7, 11, 12, 13 , and 14 in the morning and at d 11 in the evening to determine the mammary inflammatory response around the challenge in the injected versus noninjected half-udders.

\section{Weight and BCS}

Ewes were weighed on $\mathrm{d}-1,1,4,6,8,12,14$, and 22 . The reference BW was defined as the BW measured on $\mathrm{d}-1$. For the restriction period, the BW was corrected in NEB ewes by adding their average decrease in BW between $\mathrm{d}-1$ and $\mathrm{d} 1(3.3 \mathrm{~kg})$ to compensate for the decrease in digestive tract contents due to the lower DMI.

Body condition score was assessed once per phase on $\mathrm{d}-1,6,14$, and 22 using the 5 -point scale proposed by Russel et al. (1969).

\section{Blood Metabolites}

Blood samples were collected by jugular venipuncture on $\mathrm{d}-3,11,14$, and 21 before the morning milking. Samples were drawn from each ewe into blood collection tubes $(6 \mathrm{~mL}$, BD Vacutainer; Venosafe Vacutainer
Systems, Terumo Europe N.V., Leuven, Belgium) containing EDTA-K2 or heparin for plasma and were immediately placed on ice before centrifugation at 3,500 $\times g$ for 15 min at $4^{\circ} \mathrm{C}$. The plasma was harvested and stored at $-20^{\circ} \mathrm{C}$ in individual identified aliquots $(300$ $\mu \mathrm{L})$ until the analyses of each metabolite. Samples collected on EDTA were used for BHB determination, whereas samples collected on heparin were used to measure insulin, NEFA, and glucose concentrations. Plasma BHB concentration was measured in duplicate using the enzymatic method described by Williamson and Mellanby (1974). Plasma NEFA concentration was measured in duplicate using the commercially available Wako NEFA-HR2 R1 and R2 kits (Laboratoires Sobioda SAS, Montbonnot, Saint Martin, France) adapted for 96-well microplates. Plasma glucose concentration was measured in duplicate using a commercially available BioMerieux kit (reference 61,269/70; Craponne, France) adapted for 96-well microplates. Plasma insulin concentration was measured in duplicate using the protocol of a commercially available RIA kit (Insulin-CT; MP Biomedicals, Orangeburg, NY). Plasma triiodothyronine (T3) was measured using the protocol of a commercially available RIA kit (Coat-A-Count Total T3; Siemens Healthcare Diagnostic Inc., Los Angeles, CA). For statistical analyses, the BHB, NEFA, T3, and insulin data were log-transformed to normalize the data distributions.

\section{Flow Cytometry Differential Cell Counts in Milk}

For the differential cell counts before and during the inflammatory challenge, milk samples were collected on $\mathrm{d} 7,11,12,13$, and 14 in the morning and on $\mathrm{d} 11$ in the evening. Milk samples were collected 1:1 vol:vol in Alveser's solution and centrifuged at $800 \times g$ for $15 \mathrm{~min}$ at $4^{\circ} \mathrm{C}$. The pellet was washed twice in PBS, $20 \mathrm{mM}$ EDTA, and 20\% Alsever's solution, suspended in HBSS and filtered through a $40-\mu \mathrm{m}$ cell strainer. The cells were then incubated with $5 \mu M$ SYTO 13 and $5 \mu M$ Vybrant DyeCycle Ruby stain (Invitrogen, Cergy Pontoise, France) in HBSS for $30 \mathrm{~min}$ in the dark at room temperature. Flow cytometry measurements were done with a MACSQuant cytometer (Miltenyi Biotec, Bergisch Gladbach, Germany). Data were analyzed using FlowJo software (TreeStar, San Carlos, CA). Positive DNA events were gated based on Vybrant DyeCycle Ruby stain intensity and the cell types determined by side scatter and SYTO-13 labeling. The total PMNL, dead PMNL, and lymphocytes yields in milk were then calculated by multiplying the percentages by the halfudder SCC. For statistical analyses, the values were log-transformed to normalize the data distributions. 


\section{Statistical Analysis}

Linear mixed models (PROC MIXED, SAS) were used to determine the effects of genetic line (high SCS vs. low SCS) and diet (NEB vs. PEB) on the repeated continuous traits, namely test day milk production traits, SCS, BW, BCS, and blood metabolites. For milk yield and BW, the traits were analyzed as a variation from the reference value, i.e., MILKREF and reference $\mathrm{BW}$, respectively, to allow correction for the initial variation between animals and groups. The data were analyzed separately during the 4 periods (i.e., the postlambing adjustment period, the energy restriction period, the inflammation challenge period, and the postrestriction period). The models applied to all the traits were regression models and could be written in a general form as follows:

$$
\mathbf{y}=\mathbf{X} \boldsymbol{\beta}+\mathbf{Z a}+\mathbf{e}
$$

where $\mathbf{y}$ is the vector of measures for test day fat and protein contents, fat and protein yields, F:P ratio, SCS, test day variation of milk yield, BW, BCS, log NEFA, $\log \mathrm{BHB}$, glucose, $\log$ insulin, and $\log \mathrm{T} 3 ; \boldsymbol{\beta}$ is the vector of fixed effects; $\mathbf{a}$ is the random animal effect; and $\mathbf{e}$ is the random vector of residual effects. $\mathbf{X}$ and $\mathbf{Z}$ are the incidence matrices linking the phenotypic measurements to fixed effects $\boldsymbol{\beta}$ and subjects a, respectively. It is assumed that $\mathbf{a} \sim N(\mathbf{0}, \mathbf{G})$, where $\mathbf{G}$ is the subject covariance matrix, and $\mathbf{e} \sim N(\mathbf{0}, \mathbf{R})$, where $\mathbf{R}$ is the residual covariance matrix. Accordingly, $\operatorname{var}(\mathbf{y})=$ $\mathbf{Z G Z}^{\prime}+\mathbf{R}$. To account for any correlation of measures within subjects (longitudinal recording), a first-order autoregressive covariance structure was fitted to the residuals (R), as proposed by Robert-Granie et al. (2004). The following fixed effects were tested: genetic line (high SCS vs. low SCS), diet (NEB vs. PEB), litter size, sampling time point, and MILKREF. The models were first fitted without interaction terms, and then all interactions between these factors were tested. For dependent variables where only one record was available per period (i.e., for blood metabolites and BCS), the random animal effect and covariance structure of residuals were removed from the model. For repeated data obtained around the inflammatory challenge, the test day half-udder SCS, log PMNL, log dead PMNL, and log lymphocytes measured from $\mathrm{d}-4$ before challenge to $48 \mathrm{~h}$ after challenge $(\mathrm{n}=5)$ were analyzed simultaneously, using a mixed model of the general form [equation 1]. Analyses were conducted separately by half-udder (i.e., injected versus controls). Statistical differences were declared as significant or highly significant at $P<0.05$ and $P<0.01$, respectively.

\section{RESULTS}

\section{Energy Balance}

The individual energy balance was determined from the feed consumption and milk production traits. Figure 2 shows the average energy balance according to genetic line (high vs. low SCS) and diet (NEB vs. $\mathrm{PEB})$ during the experiment. As expected, the average energy balance of NEB ewes was close to $60 \%$ of their requirements during phases 2 and 3 and significantly lower than that of PEB ewes. Noteworthy, the energy balance remained stable throughout phases 2 and 3 even though the amounts of TMR provided were not readjusted after $\mathrm{d} 0$.

\section{Milk Production Traits}

The effects of genetic line (high vs. low SCS) and diet (NEB vs. $\mathrm{PEB}$ ) on milk yield variation and $\mathrm{F}: \mathrm{P}$ ratio are presented in Table 2 and illustrated with raw data in Figure 3. Milk yield was lower in NEB ewes than in PEB ewes (Figure 3A, Table 2) during phase $2(P$ $<0.0001$, LSM $-13.35 \%)$, phase $3(P<0.0001$, LSM $-24.45 \%)$, and phase $4(P<0.001$, LSM $-14.47 \%)$. Diet also had a significant effect on milk composition. For example, the F:P ratio was $35 \%$ higher in NEB ewes during energy restriction (Figure 3B, Table2) and the difference between NEB and PEB ewes was highly significant $(P<0.0001)$. Results for average protein content, fat content, protein yield and fat yield, according to genetic line and diet, are shown in the

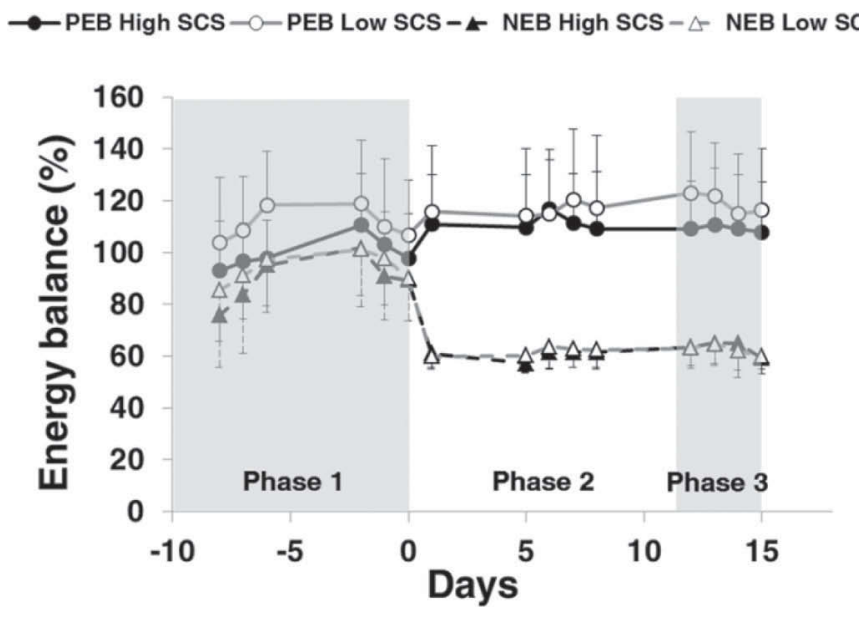

Figure 2. Energy balance in 12 high-SCS $(\boldsymbol{\Delta})$ and 12 low-SCS $(\Delta)$ ewes in negative energy balance (NEB) and 12 high-SCS (-) and 12 low-SCS $(\mathrm{O})$ ewes in positive energy balance (PEB). Time points are relative to the first day of energy restriction (d 0). Error bars indicate standard error. 
Table 2. Analysis of variance (generalized logistic mixed model) of the effect of genetic line [positive vs. negative energy balance (high vs. low SCS)], diet (PEB vs. NEB), and their interaction on different traits measured in 12 high-SCS and 12 low-SCS ewes in NEB and 12 high-SCS and 12 low-SCS ewes in PEB ${ }^{1}$

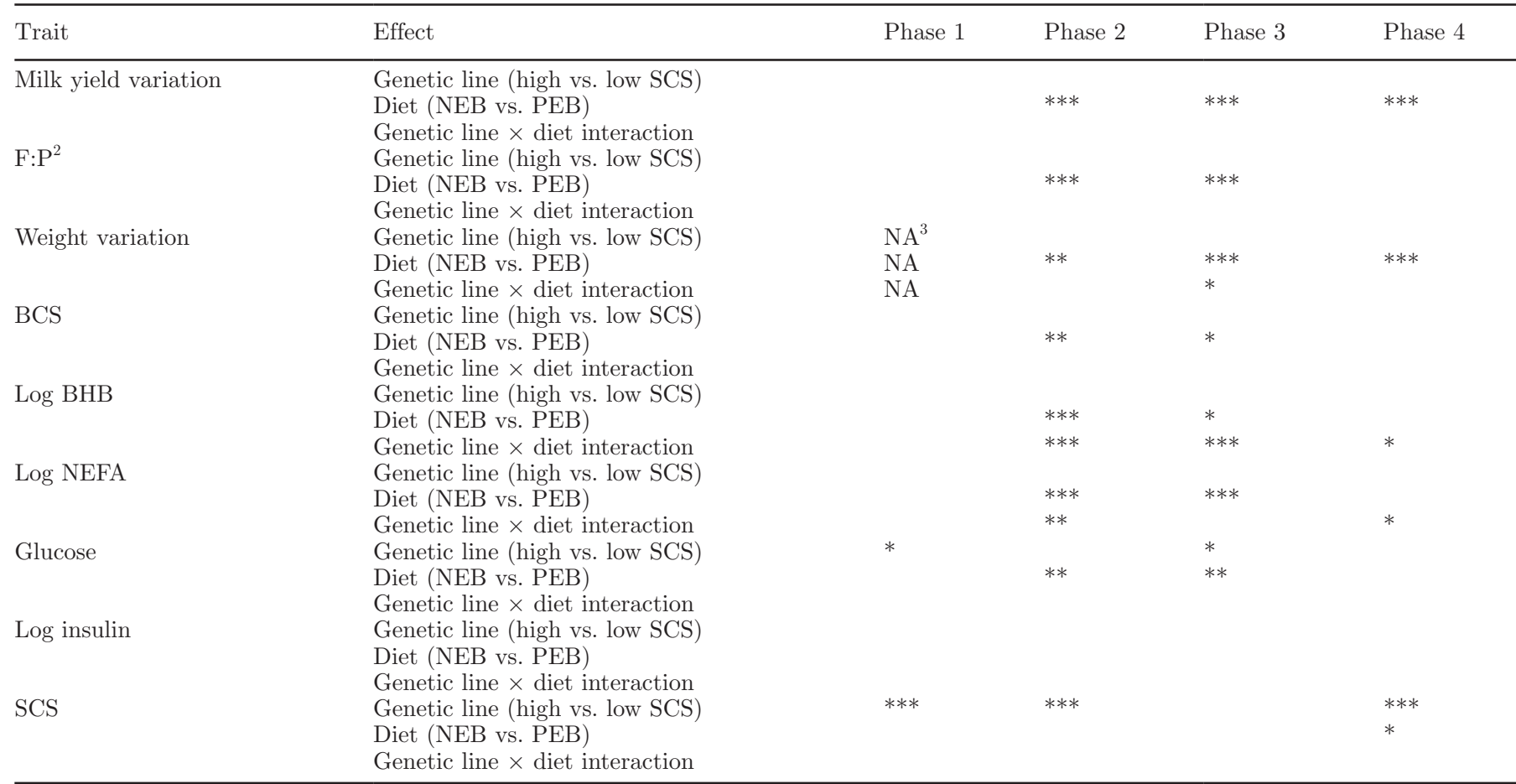

${ }^{1}$ The four different phases are described in Figure 1. For all traits and in each period of the experiment, the 3 effects were tested; significant effects were highlighted by asterisks. Significance levels for genetic line and diet were from models without interaction terms.

${ }^{2} \mathrm{~F}: \mathrm{P}=$ fat-to-protein ratio.

${ }^{3}$ Not analyzed in phase 1 (reference BW).

${ }^{*} P<0.05,{ }^{* *} P<0.01,{ }^{* * *} P<0.001$.

Supplemental Figure S1 (http://dx.doi.org/10.3168/ jds.2015-9785). Neither the genetic line nor the genetic line $\times$ diet interaction had a significant effect on milk yield or the F:P ratio during the experiment (Table 2).

\section{$B W$ and $B C S$}

Figure 4 shows the variation in BW and BCS during the experiment, according to genetic line (high vs. low SCS) and diet (NEB vs. PEB). Feed restriction decreased BW (Figure 4A) and BCS (Figure 4B) by -4.3 and $-4.9 \%$, respectively, compared with the control diet. The NEB ewes had a lower BW throughout phase $2(P<0.01)$, phase $3(P<0.0001)$, and phase $4(P<$ $0.0001)$ and a lower BCS during phase $2(P<0.01)$ and phase $3(P<0.05)$, compared with PEB ewes (Table $2)$. The genetic line did not have any significant effect on $\mathrm{BW}$ variation or BCS during the experiment. However, BW was significantly affected by the genetic line $\times$ diet interaction during phase $3(P<0.05$, Table 2$)$. In the NEB groups, BW loss was significantly higher in the high-SCS line (LSM -6.14\%) than in the lowSCS genetic line (LSM -4.02\%), whereas in the PEB groups, BW variation was limited in ewes from both low and high-SCS genetic lines. Although the genetic line $\times$ diet interaction was not significant in phase 4 , high-SCS line ewes still displayed a lower BW after the restriction challenge.

\section{Blood Metabolites}

The plasma concentrations of NEFA, BHB, glucose, and insulin are shown in Figure 5. Feed restriction increased the NEFA and BHB concentrations by 97 and $42 \%$, respectively, and decreased the glucose concentration by up to $-9 \%$ (Figures $5 \mathrm{~A}, 5 \mathrm{~B}$, and $5 \mathrm{C}$, respectively), compared with the control diet. Therefore, NEB ewes had higher plasma NEFA and BHB concentrations than PEB ewes (Table 2) during phase $2(P<0.0001$ and $P<0.001$, respectively $)$ and phase $3(P<0.0001$ and $P<0.05$, respectively). Glucose concentration was significantly lower in NEB ewes than in PEB ewes during the restriction phases $(P<$ 0.001). Despite the difference in glucose concentration observed between NEB and PEB ewes, no significant difference between the groups was observed for insulin 
concentration during the restriction phases (Figure 5D, Table 2). Nor was any significant difference observed between the groups at any point for T3 (Supplemental Figure S1 and Table S1; http://dx.doi.org/10.3168/ jds.2015-9785).

Glucose was the only metabolite tested for which the concentration was affected by genetic line (high vs. low SCS). Indeed, glucose concentration was higher in lowSCS ewes than in high-SCS ewes (Figure 5C) and the difference was significant during phase $1(P<0.05$, Table 2$)$ and phase $3(P<0.05$, Table 2$)$. Importantly, the statistical analysis (Table 2 ) revealed a significant genetic line $\times$ diet interaction for NEFA (Figure 5A) and BHB (Figure 5B) concentrations during phase 2 $(P<0.01$ and $P=0.0001$, respectively, Table 2$)$. The interaction was still significant during phase 3 for $\mathrm{BHB}$

- PEB High SCS $-\circ-$ PEB Low SCS $-\downarrow$ NEB High SCS $-\triangle$ NEB Low SCS

A

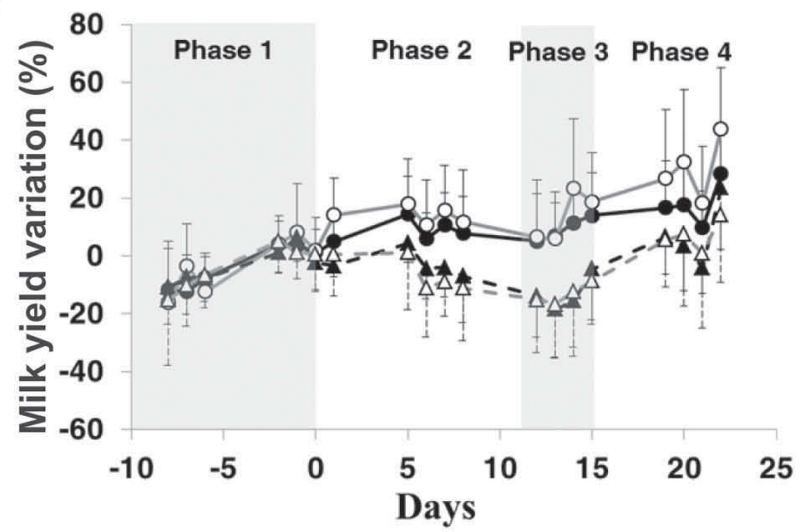

$\rightarrow$ PEB High SCS $-0-$ PEB Low SCS $-\downarrow$ NEB High SCS $-\triangle$ NEB Low SCS

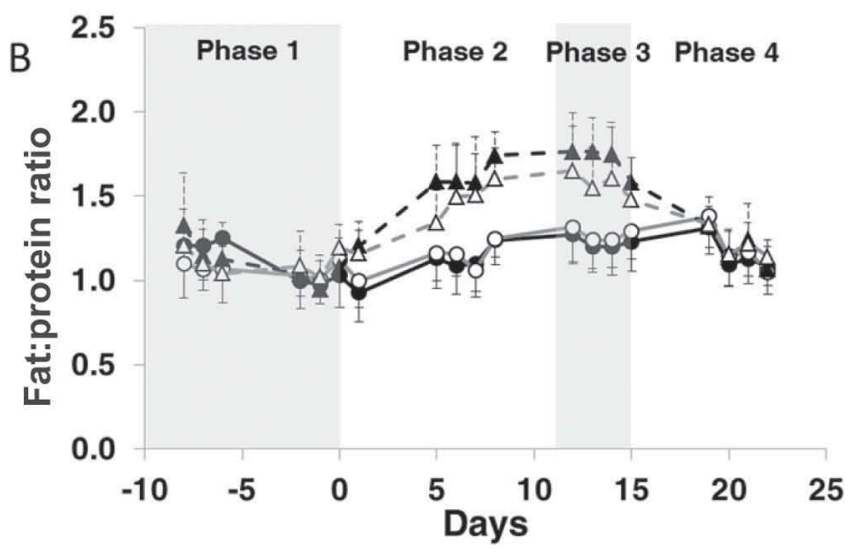

Figure 3. Milk yield variation relative to the arithmetic mean of the last 3 milk yields recorded during phase 1 (A) and fat:protein ratio (B) in 12 high-SCS $(\boldsymbol{\Delta})$ and 12 low-SCS $(\Delta)$ ewes in negative energy balance (NEB) and 12 high-SCS $(\bullet)$ and 12 low-SCS $(\bigcirc)$ ewes in positive energy balance (PEB). Time points are relative to the first day of energy restriction (d 0). Error bars indicate standard error.
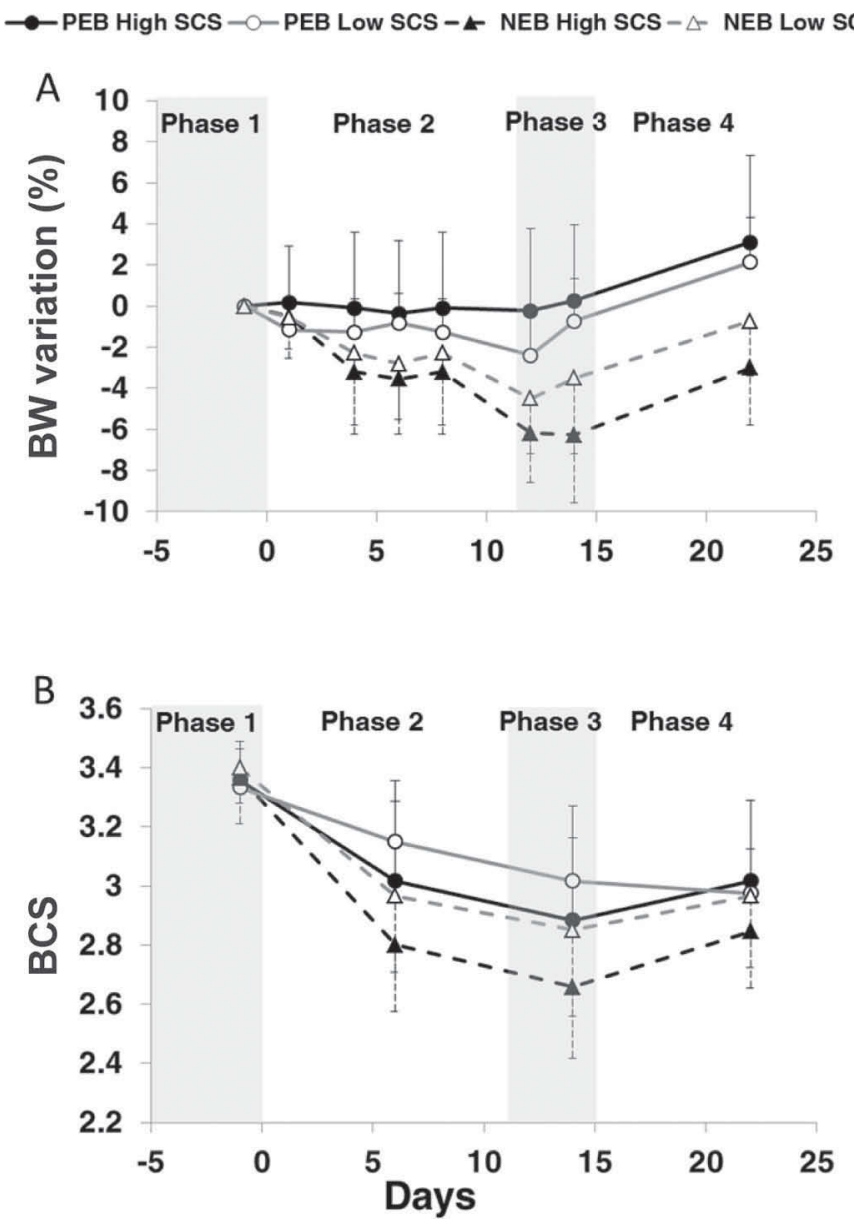

Figure 4. Weight variation relative to $\mathrm{d}-1$ (A) and BCS (B) in 12 high-SCS $(\mathbf{\Lambda})$ and 12 low-SCS $(\Delta)$ ewes in negative energy balance $(\mathrm{NEB})$ and 12 high-SCS $(\bullet)$ and 12 low-SCS $(\bigcirc)$ ewes in positive energy balance (PEB). Time points are relative to the first day of energy restriction (d 0). Body weight of NEB ewes was corrected for the decrease in digestive contents during phases 2 and 3. Error bars indicate standard error.

concentration $(P<0.001)$ and remained a tendency for NEFA concentration $(P=0.09)$. High-SCS NEB ewes had higher BHB and NEFA concentrations than low-SCS NEB ewes, whereas BHB concentrations in both low and high-SCS PEB groups remained similar throughout the experiment. The interactions for both NEFA and BHB concentrations were still significant during phase 4 .

\section{Mammary Inflammation}

One ewe showed local and general signs of mastitis on $\mathrm{d} 14$; therefore, the data collected from the ewe in phases 3 and 4 were discarded from the statistical analysis. Three out of the 48 injected half-udders presented higher SCS (between 3.5 and 4.5) before the inflammatory challenge. These half-udders were retained for 


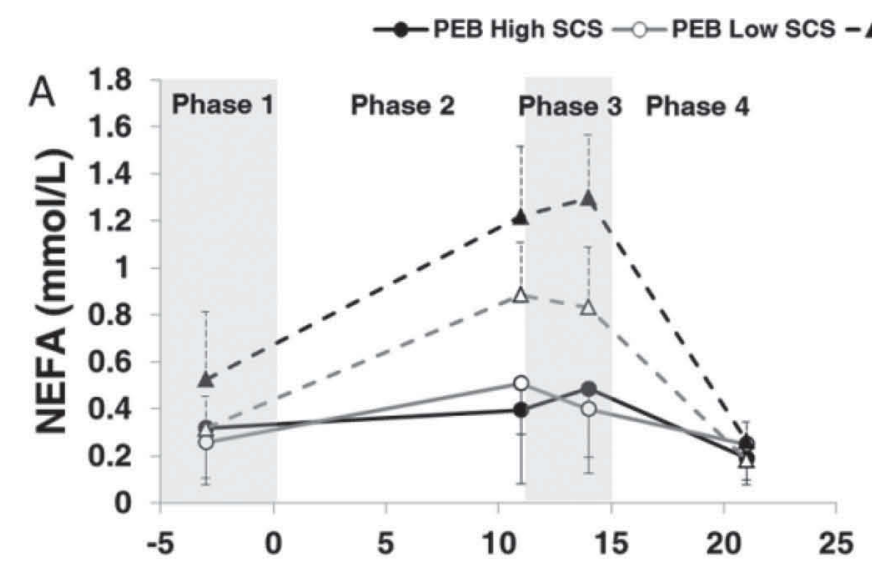

NEB High SCS $-\triangle$ NEB Low SCS
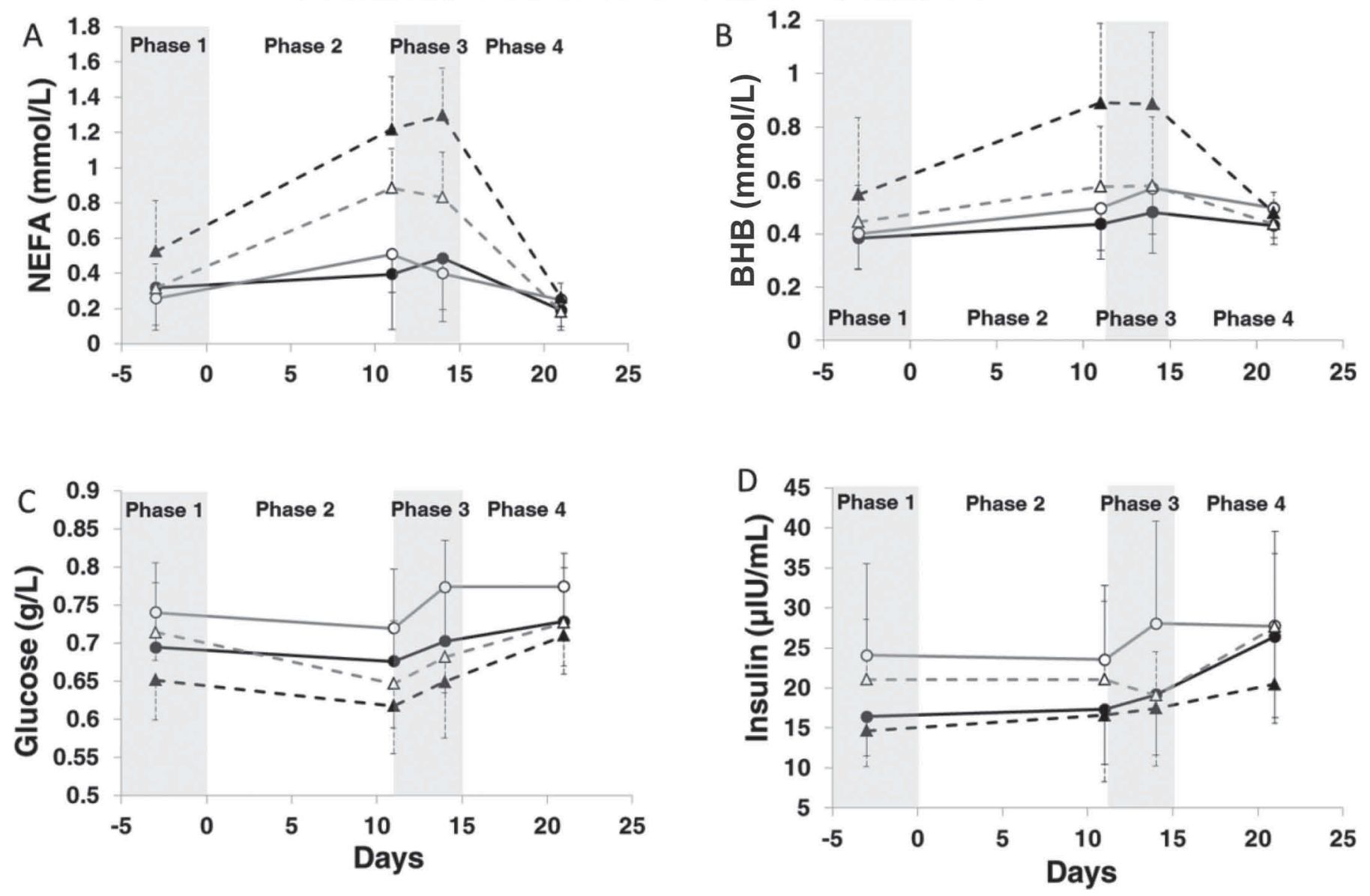

Figure 5. Plasma concentrations of nonesterified fatty acids (NEFA; A), BHB (B), glucose (C), and insulin (D) in 12 high-SCS (ム) and 12 low-SCS $(\Delta)$ ewes in negative energy balance (NEB) and 12 high-SCS $(\bullet)$ and 12 low-SCS $(\bigcirc)$ ewes in positive energy balance (PEB). Time points are relative to the first day of energy restriction (d 0). Error bars indicate standard error.

analysis because the inflammatory challenge induced an intense and strong inflammatory response (average SCS of 9.8 in the injected half-udder), well above the residual inflammation linked to chronic infection.

Figure 6 shows SCS during the experiment according to genetic line (high vs. low SCS) and diet (NEB vs. PEB). Ewes receiving the NEB diet had an unexpected lower SCS than PEB ewes during phase $4(P<0.05$, LSM -14.7\%). Statistical analysis (Table 2) showed that high-SCS ewes had a higher SCS than low-SCS ewes in phases 1, 2, and 4. However, genetic line had no significant effect on SCS during phase 3. Indeed, similar SCS values were obtained for both genetic lines during the inflammatory challenge. No genetic line $\times$ diet interaction was observed for whole-udder milk SCS during the experiment.

The SCS, lymphocytes, PMNL, and dead PMNL counts in both injected and control half-udders were scrutinized once during phase 2 and 4 times during

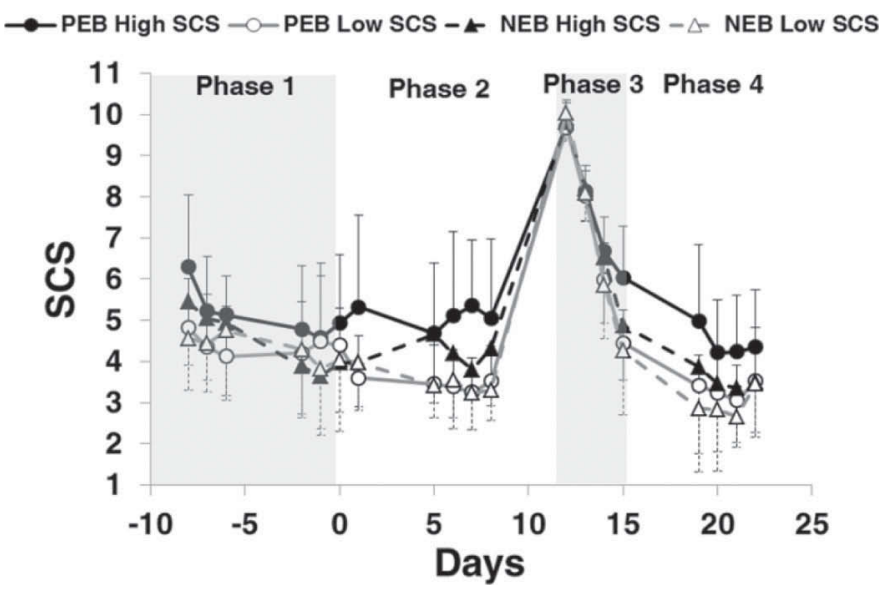

Figure 6. The SCS in 12 high-SCS $(\boldsymbol{\Delta})$ and 12 low-SCS $(\Delta)$ ewes in negative energy balance (NEB) and 12 high-SCS $(\bullet)$ and 12 low-SCS (O) ewes in positive energy balance (PEB). Time points are relative to the first day of energy restriction (d 0). Mastitis challenge was administered at d 11. Error bars indicate standard error. 

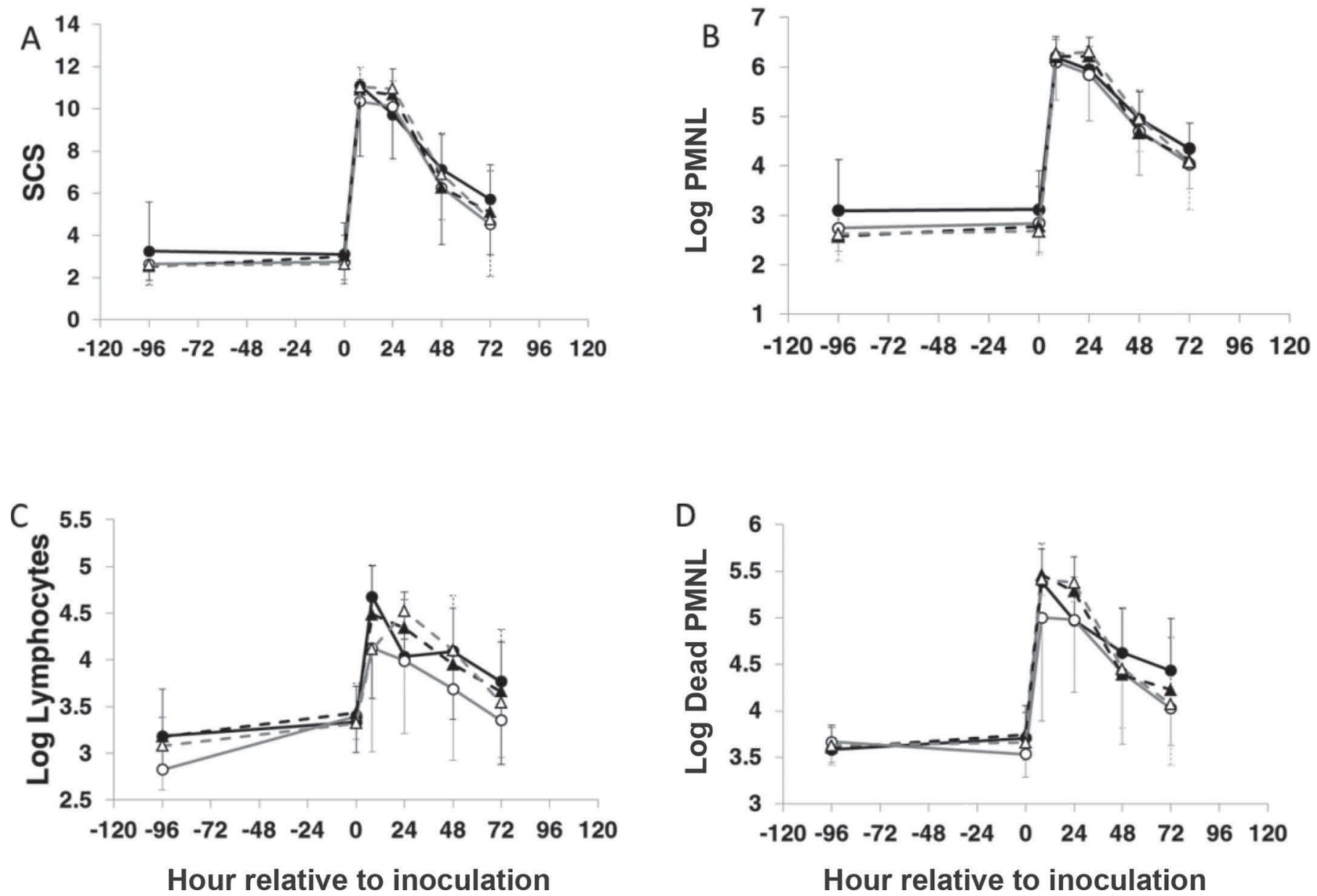

Figure 7. The SCS (A), log polymorphonuclear neutrophils (PMNL; B), log lymphocytes (C), and log dead PMNL (D) in injected half-udder of 12 high-SCS $(\boldsymbol{\Delta})$ and 12 low-SCS $(\Delta)$ ewes in negative energy balance (NEB) and 12 high-SCS $(\bullet)$ and 12 low-SCS $(O)$ ewes in positive energy balance (PEB). Time points are relative to the hour of injection. Error bars indicate standard error.

phase 3. Neither diet nor genetic line $\times$ diet interaction had any significant effect on SCS, lymphocytes, PMNL, or dead PMNL counts in noninjected half-udders, as shown in Supplemental Figure S2 (http://dx.doi. org/10.3168/jds.2015-9785). However, the noninjected half-udders of high-SCS ewes had higher SCS, lymphocytes, PMNL, and dead PMNL counts than those of low-SCS ewes (Supplemental Table S2; http://dx.doi. org/10.3168/jds.2015-9785).

The SCS, lymphocytes, PMNL, and dead PMNL counts in the injected half-udders of all ewes increased at $8 \mathrm{~h}$ postinjection then decreased between 24 and $72 \mathrm{~h}$. The effect of diet (NEB vs. PEB) on the injected half-udder was significant for dead PMNL counts (Figure 7B, $P<0.05$ ) but only had a tendency for lymphocyte counts (Figure $7 \mathrm{C}, P=0.06$ ). Indeed, NEB ewes had slightly higher dead PMNL counts and lymphocytes counts than PEB ewes $(+3.2$ and $+3.6 \%$, respectively). However, no difference was observed between the injected half-udders of PEB and NEB ewes for SCS (Figure 7A) or PMNL (Figure 7D).

The effect of genetic line (high vs. low SCS) was not significant for SCS, PMNL, or dead PMNL counts in the injected half-udder during the $48 \mathrm{~h}$ postinjection. However, high-SCS ewes had a higher lymphocytes count than low-SCS ewes $(+4 \%)$. The genetic line $\times$ diet interaction did not significantly affect SCS, lymphocytes, PMNL, or dead PMNL counts in the injected half-udder during the $48 \mathrm{~h}$ postinjection.

\section{DISCUSSION}

\section{Consequences of a Dietary-Induced NEB in Ewes}

As expected, reducing the energy supply in lactating ewes resulted in an average energy balance of approxi- 
mately $60 \%$ and produced conditions closely related to metabolic impairment during early lactation in dairy cattle (Rastani et al., 2001).

In the present study, restriction led to a decrease in milk yield as reported in Gross et al. (2011), who studied energy-restricted Holstein cows with a similarly induced NEB during mid lactation. In their study, the decline in milk yield during restriction was only about $10 \%$, whereas it was $25 \%$ in NEB ewes in our study. The selection for higher milk production achieved over recent decades in Holstein cows, and to some extent in Lacaune dairy sheep, has probably resulted in greater homeorhetic control of metabolism to ensure that endogenous and dietary nutrients are directed to the mammary gland for lactogenesis. This might explain a moderate decrease in milk production despite the persistence of induced NEB. As in Gross et al. (2011), F:P ratio increased during restriction in NEB ewes. This difference was due to a decrease in milk protein content and an increase in fat content.

Decrease in BW is mainly due to the mobilization of adipose tissue during early lactation. In the present study, BW was corrected to ensure that the measured BW loss was not due to the decreased weight of the digestive tract contents. The decline in ewe BW during the deliberately induced NEB in the present study was only $4.3 \%$ in contrast to the $8 \%$ decrease reported by Gross et al. (2011) where the induced NEB was similar but the BW was not corrected for the decrease in digestive tract contents. Moreover, the fact that the energy restriction period in our study was only 2 wk compared with 3 wk in the study by Gross et al. (2011) might partly explain this difference.

The energy balance remained stable throughout the restriction period, even though the amounts of TMR were not readjusted, and this could be due to the way the energy balance was determined. Indeed, energy balance is dependent on energy requirements and thus on BW, milk yield, and fat and protein contents. Even if milk yield and BW decreased during restriction, the stability of the energy requirements and hence of the energy balance over time could be due to the increase in fat content. Energy restriction in ewes also resulted in significant modifications in the concentrations of blood metabolites, as have already been described in feed-restricted cattle.

The NEB around parturition is known to lead to extensive mobilization of adipose triacylglycerols to meet energy requirements. High concentrations of plasma NEFA are therefore produced from mobilized adipose tissue triacylglycerols that can be taken up by the liver and oxidized to produce ketone bodies (Dann et al., 2006; Goff, 2006). Our study confirmed that energy restriction in ewes was associated with increased plasma
NEFA and BHB concentrations during early lactation, in accordance with numerous studies conducted in dairy cows (Suriyasathaporn et al., 2000; Gross et al., 2011). Indeed, in NEB ewes, BHB was higher by $42 \%$ and NEFA by $97 \%$ than in ewes receiving the control diet. The NEFA and BHB concentrations in our PEB and NEB ewes were similar to those reported by Moyes et al. (2009) in Holstein cows restricted to $60 \%$ of their energy requirement. The metabolic profile of primiparous Lacaune sheep, from the same flock used in the present study, had already been determined 1 wk before lambing until the end of lactation (González-García et al., 2015). In the present study, the NEFA and BHB concentrations in PEB ewes remained stable throughout the experiment and averaged 0.3 and $0.5 \mathrm{mmol} / \mathrm{l}$, respectively. In contrast, González-García et al. (2015) reported higher NEFA and BHB concentrations (0.8 and $0.6 \mathrm{mmol} / \mathrm{L}$, respectively) $28 \mathrm{~d}$ after lambing. The lower NEFA and BHB concentrations measured in our study could be explained by the fact that the lambs were separated from their dams after colostrum intake, whereas the lambs were suckled in the experiment described by González-García et al. (2015). The 28-d suckling period may indeed have augmented the energy required for lactation and have increased the energy deficit and thus the NEFA and BHB concentrations.

The decrease in plasma glucose concentration resulting from energy restriction was probably due to the smaller amount of propionate produced in the rumen, due to the lower DMI, and the replacement of barley by a protein concentrate to meet protein requirements. Indeed, glycemia was reduced by $8.5 \%$ on average in NEB ewes, whereas Moyes et al. (2009) found that NEB induction had no effect on the homeostatic control of blood glucose during mid lactation. However, these authors induced NEB by decreasing the amount of feed but without changing its composition, which affected protein supply but had less effect on starch intake than our restriction method. Despite the significant difference in plasma glucose concentration between NEB and $\mathrm{PEB}$ ewes, no difference in plasma insulin concentration was observed during restriction. The insulin concentrations measured in the present experiment were within the range previously reported in primiparous ewes from the same flock (González-García et al., 2015).

\section{Response to the Inflammatory Challenge in Energy-Restricted Ewes}

Energy restriction did not modify the intense inflammatory response induced by Staphylococcus-associated ligands in our study. Similarly, no difference in milk SCS between NEB and PEB cows was reported during Streptococcus-associated mastitis by Moyes et al. 
(2009). However, in our study, the dead PMNL counts were slightly but significantly higher in NEB than PEB ewes during the challenge whereas no difference was observed for PMNL counts. This suggests that neutrophil apoptosis might be differently regulated according to energy balance. Such an explanation is in agreement with Piepers and De Vliegher (2013), who reported significantly higher percentages of milk and blood PMNL apoptosis in nonsupplemented cows during the periparturient period (reflecting a potential reduction in innate immune capacity), as compared with cows orally supplemented with medium-chain FA.

\section{Response to the Inflammatory Challenge in Ewes with Different Backgrounds in Mastitis Susceptibility}

As expected, high-SCS ewes had higher SCS compared with low-SCS ewes in accordance with Rupp et al. (2009). Monthly SCS measurements provide a good indirect indicator of mastitis. Thus, the different mastitis-susceptibility backgrounds of the 2 genetic lines (high vs. low SCS) were confirmed by their different SCS levels. During the inflammatory challenge, SCS increased sharply in the injected half-udder. As milk SCS mainly reflects the number of neutrophils that migrate from the blood to the mammary gland, the $\mathrm{Pam}_{3} \mathrm{CSK}_{4} /$ MDP combination triggered a strong recruitment. Furthermore, an acute recruitment of neutrophils and lymphocytes in response to the challenge was confirmed by flow cytometry. Surprisingly, no difference for SCS or neutrophils recruitments was observed between the 2 lines. The ability of neutrophils to migrate to the site of infection and engulf invading pathogens is however critical to the efficiency of the innate immune response (Rainard and Riollet, 2006). Thus, the neutrophils from both SCS lines exhibited similar abilities to migrate to the site of inflammation. Consistent with our results, Bonnefont et al. (2011) reported similar SCC in these 2 lines during the $48 \mathrm{~h}$ after Staphylococcus inoculations even if the bacteriological titer was lower in low-SCS ewes. The 2 SCS lines might display the same neutrophil recruitment kinetics in the mammary gland in response to an invading pathogen, but a difference in functionality, such as phagocytosis and killing abilities, could in turn explain the difference in susceptibility to mastitis. Further studies are necessary to test this hypothesis.

\section{Consequences of a NEB in Ewes with Different Genetic Backgrounds in Mastitis Susceptibility}

To our knowledge, this is the first report of a difference in metabolic response to an energy restriction in animals with different genetic backgrounds in mastitis susceptibility. An interesting interaction on metabolic parameters was highlighted between diet and genetic line (high vs. low SCS). High-SCS ewes exhibited a slightly greater decrease in BW and increase in NEFA concentration than low-SCS ewes in response to NEB. As an increase in NEFA concentration reflects a mobilization of adipose tissue, this phenomenon was slightly more intense in high-SCS ewes than in low-SCS ewes. Above all, high-SCS ewes produced much more BHB during energy restriction than low-SCS ewes, which suggests a greater production of ketone bodies or a relative incapacity to use these substrates. According to Suriyasathaporn et al. (2000), insufficient oxaloacetate is available during the hypoglycemic state for synthesis of citrate from acetyl-CoA to enter the TCA cycle. Consequently, acetyl-CoA is removed via ketone body synthesis as long as the energy supply remains deficient. Ketone body synthesis was thus greater in high-SCS than in low-SCS ewes during energy restriction. Moreover, the plasma glucose concentration was slightly lower in high-SCS ewes than in low-SCS ewes before energy restriction and during the inflammatory challenge, which would support the hypothesis that acetyl-CoA accumulation was greater in high-SCS ewes than in low-SCS ewes.

Selection based on extreme breeding values for SCS was associated with a different metabolic response to energy restriction. This finding is in accordance with previous studies that demonstrated positive genetic correlations between mastitis and ketosis (Zwald et al., 2004; Heringstad et al., 2005). Genini et al. (2011) also showed that pathways related to immune response and lipid metabolism were altered in ruminants infected with mammary gland pathogens. Two hypotheses can be formulated in the light of these results. The first hypothesis is that high-SCS ewes may differ from low-SCS ewes in their genetic background for lipid metabolism, resulting in intense NEFA and BHB synthesis during energy restriction. The difference between the 2 metabolisms would lead to the variation in mastitis susceptibility. This hypothesis is supported by Suriyasathaporn et al. (1999), who demonstrated that BHB and NEFA impair immune cell functions in vitro. The second hypothesis is that high-SCS ewes may have higher energy requirements than low-SCS ewes due in part to their higher immune energy expenditure. This would enhance the energy demand, result in greater mobilization of adipose tissue and thereby increase NEFA and BHB synthesis. Glucose is the primary fuel used by bovine leukocytes (Weisdorf et al., 1982), which is consistent with our observations of a higher milk leukocyte count and lower glucose concentration in high-SCS ewes than 
in low-SCS ewes. Acetyl-CoA accumulation and BHB synthesis might therefore have been amplified in highSCS ewes.

Further studies are needed to disentangle these hypotheses and better understand the mechanisms underlying the genetic association between mastitis susceptibility and energy metabolism.

\section{CONCLUSIONS}

Induced NEB in lactating ewes yielded similar results to those previously observed in dairy cows. However, to our knowledge, this is the first report of a difference in metabolic response to an energy restriction in ruminants with different genetic backgrounds in mastitis susceptibility. Indeed, mastitis-susceptible ewes showed a greater decrease in BW and higher NEFA and $\mathrm{BHB}$ concentrations than mastitis-resistant ewes when subjected to NEB, thus showing the extensive mobilization of body reserves and intense ketone body synthesis occurring in susceptible sheep. These preliminary results reinforce the hypothesis of a genetic association between mastitis susceptibility and energy metabolism, and open the way to further studies on the biological basis of the association between metabolism and immunity. From a population perspective, successful selection to achieve global robustness (healthy and high-yield dairy ruminants) is an issue for livestock, all the more if environmental conditions become more challenging. Our finding suggest that selection for low SCS involves having more robust animals, with potentially fewer metabolic disorders and better response to nutrition challenge. This hypothesis should be addressed in the future.

\section{ACKNOWLEDGMENTS}

This work was supported by grants from the RUMINFLAME project, as part of the INRA MetaProgramme Gestion Intégrée de la Santé Animale (INRA, Paris, France). The authors are grateful to Philippe Hassoun (INRA SELMET, Montpellier, France) for his advice on the experiment and for reviewing the paper. In addition, gratitude is extended to Jeremie Gozlan, Claudia Ribeiro, and the technical staff of La Fage experimental farm (Roquefort sur Soulzon, France) for assisting with technical support, animal care, and data collection.

\section{REFERENCES}

Barkema, H. W., M. J. Green, A. J. Bradley, and R. N. Zadoks. 2009. Invited review: The role of contagious disease in udder health. J. Dairy Sci. 92:4717-4729. http://dx.doi.org/10.3168/jds.2009-2347.
Bergonier, D., R. de Crémoux, R. Rupp, G. Lagriffoul, and X. Berthelot. 2003. Mastitis of dairy small ruminants. Vet. Res. 34:689-716. http://dx.doi.org/10.1051/vetres:2003030.

Bonnefont, C. M., M. Toufeer, C. Caubet, E. Foulon, C. Tasca, M.-R. Aurel, D. Bergonier, S. Boullier, C. Robert-Granié, G. Foucras, and R. Rupp. 2011. Transcriptomic analysis of milk somatic cells in mastitis resistant and susceptible sheep upon challenge with Staphylococcus epidermidis and Staphylococcus aureus. BMC Genomics 12:208. http://dx.doi.org/10.1186/1471-2164-12-208.

Dann, H. M., N. B. Litherland, J. P. Underwood, M. Bionaz, A. D'Angelo, J. W. McFadden, and J. K. Drackley. 2006. Diets during far-off and close-up dry periods affect periparturient metabolism and lactation in multiparous cows. J. Dairy Sci. 89:3563-3577. http://dx.doi.org/10.3168/jds.S0022-0302(06)72396-7.

Drackley, J. K. 1999. Biology of dairy cows during the transition period: The final frontier? J. Dairy Sci. 82:2259-2273. http://dx.doi. org/10.3168/jds.S0022-0302(99)75474-3.

Genini, S., B. Badaoui, G. Sclep, S. C. Bishop, D. Waddington, M.H. Pinard van der Laan, C. Klopp, C. Cabau, H.-M. Seyfert, W. Petzl, K. Jensen, E. J. Glass, A. de Greeff, H. E. Smith, M. A. Smits, I. Olsaker, G. M. Boman, G. Pisoni, P. Moroni, B. Castiglioni, P. Cremonesi, M. Del Corvo, E. Foulon, G. Foucras, R. Rupp, and E. Giuffra. 2011. Strengthening insights into host responses to mastitis infection in ruminants by combining heterogeneous microarray data sources. BMC Genomics 12:225 http:// dx.doi.org/10.1186/1471-2164-12-225.

Goff, J. P. 2006. Major advances in our understanding of nutritional influences on bovine health. J. Dairy Sci. 89:1292-1301. http:// dx.doi.org/10.3168/jds.S0022-0302(06)72197-X.

González-García, E., A. Tesniere, S. Camous, F. Bocquier, F. Barillet, and P. Hassoun. 2015. The effects of parity, litter size, physiological state, and milking frequency on the metabolic profile of Lacaune dairy ewes. Domest. Anim. Endocrinol. 50:32-44. http:// dx.doi.org/10.1016/j.domaniend.2014.07.001.

Gross, J., H. A. van Dorland, R. M. Bruckmaier, and F. J. Schwarz. 2011. Performance and metabolic profile of dairy cows during a lactational and deliberately induced negative energy balance with subsequent realimentation. J. Dairy Sci. 94:1820-1830. http:// dx.doi.org/10.3168/jds.2010-3707.

Hassoun, P., and F. Bocquier. 2014. Alimentation des ovins. Quae, Versailles, France.

Heringstad, B., Y. M. Chang, D. Gianola, and G. Klemetsdal. 2005. Genetic analysis of clinical mastitis, milk fever, ketosis, and retained placenta in three lactations of Norwegian red cows. J. Dairy Sci. 88:3273-3281. http://dx.doi.org/10.3168/jds.S00220302(05) 73010-1.

Jánosi, S., M. Kulcsár, P. Kóródi, L. Kátai, J. Reiczigel, S. J. Dieleman, J. A. Nikolic, G. Sályi, P. Ribiczey-Szabó, and G. Huszenicza. 2003. Energy imbalance related predisposition to mastitis in group-fed high-producing postpartum dairy cows. Acta Vet. Hung. 51:409-424. http://dx.doi.org/10.1556/AVet.51.2003.3.14.

Koeck, A., J. Jamrozik, F. S. Schenkel, R. K. Moore, D. M. Lefebvre, D. F. Kelton, and F. Miglior. 2014. Genetic analysis of milk $\beta$-hydroxybutyrate and its association with fat-to-protein ratio, body condition score, clinical ketosis, and displaced abomasum in early first lactation of Canadian Holsteins. J. Dairy Sci. 97:72867292. http://dx.doi.org/10.3168/jds.2014-8405.

Mallard, B. A., J. C. Dekkers, M. J. Ireland, K. E. Leslie, S. Sharif, C. Lacey Vankampen, L. Wagter, and B. N. Wilkie. 1998. Alteration in immune responsiveness during the peripartum period and its ramification on dairy cow and calf health. J. Dairy Sci. 81:585595. http://dx.doi.org/10.3168/jds.S0022-0302(98)75612-7.

Moyes, K. M., J. K. Drackley, J. L. Salak-Johnson, D. E. Morin, J. C. Hope, and J. J. Loor. 2009. Dietary-induced negative energy balance has minimal effects on innate immunity during a Streptococcus uberis mastitis challenge in dairy cows during mid lactation. J. Dairy Sci. 92:4301-4316. http://dx.doi.org/10.3168/jds.2009-2170.

Nyman, A.-K., U. Emanuelson, K. Holtenius, K. L. Ingvartsen, T. Larsen, and K. P. Waller. 2008. Metabolites and immune variables associated with somatic cell counts of primiparous dairy cows. J. Dairy Sci. 91:2996-3009. http://dx.doi.org/10.3168/jds.2007-0969. 
Piepers, S., and S. De Vliegher. 2013. Oral supplementation of medium-chain fatty acids during the dry period supports the neutrophil viability of peripartum dairy cows. J. Dairy Res. 80:309-318. http://dx.doi.org/10.1017/S0022029913000228.

Rainard, P., and C. Riollet. 2006. Innate immunity of the bovine mammary gland. Vet. Res. 37:369-400. http://dx.doi.org/10.1051/ vetres:2006007.

Rastani, R. R., S. M. Andrew, S. A. Zinn, and C. J. Sniffen. 2001. Body composition and estimated tissue energy balance in Jersey and Holstein cows during early lactation. J. Dairy Sci. 84:12011209. http://dx.doi.org/10.3168/jds.S0022-0302(01)74581-X.

Robert-Granie, C., J. Foulley, E. Maza, and R. Rupp. 2004. Statistical analysis of somatic cell scores via mixed model methodology for longitudinal data. Anim. Res. 53:259-273.

Rupp, R., D. Bergonier, S. Dion, M. C. Hygonenq, M. R. Aurel, C. Robert-Granié, and G. Foucras. 2009. Response to somatic cell count-based selection for mastitis resistance in a divergent selection experiment in sheep. J. Dairy Sci. 92:1203-1219. http:// dx.doi.org/10.3168/jds.2008-1435.

Russel, A. J. F., J. M. Doney, and R. G. Gunn. 1969. Subjective assessment of body fat in live sheep. J. Agric. Sci. 72:451-454. http://dx.doi.org/10.1017/S0021859600024874.

Scalia, D., N. Lacetera, U. Bernabucci, K. Demeyere, L. Duchateau, and C. Burvenich. 2006. In vitro effects of nonesterified fatty acids on bovine neutrophils oxidative burst and viability. J. Dairy Sci. 89:147-154. http://dx.doi.org/10.3168/jds.S0022-0302(06)72078-
Shook, G. E. 2006. Major advances in determining appropriate selection goals. J. Dairy Sci. 89:1349-1361. http://dx.doi.org/10.3168/ jds.S0022-0302(06)72202-0.

Suriyasathaporn, W., A. J. J. M. Daemen, E. N. NoordhuizenStassen, S. J. Dieleman, M. Nielen, and Y. H. Schukken. 1999. $\beta$-hydroxybutyrate levels in peripheral blood and ketone bodies supplemented in culture media affect the in vitro chemotaxis of bovine leukocytes. Vet. Immunol. Immunopathol. 68:177-186. http://dx.doi.org/10.1016/S0165-2427(99)00017-3.

Suriyasathaporn, W., C. Heuer, E. N. Noordhuizen-Stassen, and Y. H. Schukken. 2000. Hyperketonemia and the impairment of udder defense: A review. Vet. Res. 31:397-412. http://dx.doi.org/10.1051/ vetres:2000128.

Weisdorf, D. J., P. R. Craddock, and H. S. Jacob. 1982. Granulocytes utilize different energy sources for movement and phagocytosis. Inflammation 6:245-256. http://dx.doi.org/10.1007/BF00916406.

Williamson, D. H., and J. Mellanby. 1974. D-(-)-3-Hydroxybutyrate. Pages 1836-1839 in Methods of Enzymatic Analysis. 2nd English ed. H. U. Bergmeyer, ed., in collaboration with K. Gawehn. Academic Press Inc., New York, NY.

Zwald, N. R., K. A. Weigel, Y. M. Chang, R. D. Welper, and J. S. Clay. 2004. Genetic selection for health traits using producer-recorded data. II. Genetic correlations, disease probabilities, and relationships with existing traits. J. Dairy Sci. 87:4295-4302. http:/ dx.doi.org/10.3168/jds.S0022-0302(04)73574-2. 